\title{
Comparative study between crack tip opening displacement techniques by statistical analysis
}

\author{
Matheus Lothar Schmidt ${ }^{1 *}$ \\ Guilherme Vieira Braga Lemos ${ }^{1}$ (D) \\ Daniel Antonio Kapper Fabricio ${ }^{2}$ \\ Afonso Reguly
}

\begin{abstract}
Standardized tests may not always achieve all their analytical objectives. Particularly to structural integrity, where a reproduction of the practical occurrences of the industry is desired, new techniques are being developed. Therefore, this work aims at evaluating fracture toughness in tensile armour through four measurement methodologies (standard, video, laser and stretch zone (SZ)) to obtain crack tip opening displacement (CTOD), and compares their responses by ANOVA and Duncan's tests. The findings showed equivalence between the standard and other approaches, thus allowing distinct methods for fracture toughness evaluation.
\end{abstract}

Keywords: Fracture toughness; Crack tip opening displacement; Tensile armour wire; Statistical analysis.

\section{Introduction}

Methodologies for determination of critical or initial crack size are used to offer reliable data for structural integrity projects. In this context, a standard technique enables a comparison of the methods adopted worldwide. However, standards might not achieve results that correspond faithfully to the real fracture toughness characteristics. Due to those difficulties, authors suggest the application of non-standardized methods for obtaining fracture toughness of ductile materials; avoiding numerical simulation, do not depending on the specimen geometry, and could be applied on metallic structures containing a defect [1-3].

Among the existing methods for fracture toughness investigation, the method for obtaining $\delta_{5}$, developed by Schwalbe, is a technique for CTOD measurement where the values are given by lateral measurements on the specimens, starting from two distinct points $2.5 \mathrm{~mm}$ perpendicularly from the tip of the fatigue precrack. Indentations are performed on one lateral surface of the specimen, and a micro-hardness durometer is used to indicate the fixation position of the clip-gage at the beginning of the test $[1,4]$. The advantages of this method imply that the measurements are performed directly at the crack tip, without the need for further calculations or mathematical modelling. Besides, the method allows the application of any specimen geometry or structure that contains a crack. Moreover, both R-curves and fracture toughness values can be obtained concerning critical and initiation stages of crack growth [5].
As an alternative to the methods for obtaining fracture toughness, especially when the material has high plasticity at the crack tip, it was proposed to evaluate the critical crack size length by the blunting line field. These methodologies (based on the fracture surface measurement) are independent of geometric factors and only consider the loading mode [6].

The crack initiation on ductile materials is characterized by the presence of a zone in which it is possible to observe the stretching of microvoids at the fracture surface. This effect is due to the crack tip blunting process, where through a pre-existent crack (precrack), the material is submitted to a critical strain, promoting microvoids above the crack tip, which coalescence causes the crack opening and starting an unstable crack growth $[3,7]$.

The band created by the crack tip blunting is named as Stretch Zone (SZ) that is measured through Scanning Electron Microscope (SEM). Studies showed that CTOD values obtained through SZ measurements are inferior to the Schwalbe and the standardized methods, demonstrating that the remote techniques do not correspond devotedly to the real events, although providing good response and being essential procedures to practical approaches in structural integrity assessment tip $[2,8]$.

The current study aims at evaluating different CTOD techniques for fracture toughness in a tensile armour wire. Moreover, through statistical analysis, this work compares the fracture toughness values by the novel methodologies with the outcomes provided by ASTM E1820 standard [9].

\footnotetext{
${ }^{1}$ Laboratório de Metalurgia Física - LAMEF, Programa de Pós-graduação em Engenharia de Minas, Metalúrgica e de Materiais - PPGE3M, Universidade Federal do Rio Grande do Sul - UFRGS, Porto Alegre, RS, Brasil.

Instituto Federal de Educação, Ciência e Tecnologia de Santa Catarina, IFSC, Chapecó, SC, Brasil.

*Corresponding author: matheuslothars@hotmail.com
} 


\section{Materials and methods}

The tensile armour is a fundamental part of flexible risers, which are pipes projected to suppress dynamics efforts in the oil and gas exploitation. In this context, flexible risers may have to support static loading, either for tensile and flexion modes. The armours are made by high-strength carbon steel helically arranged, with chemical composition given in Table 1 [10].

To determine the materials' mechanical properties, which are used to calculate the CTOD through ASTM E1820 standard, three subsize specimens were machined in the longitudinal direction of the wire. Specimen geometry was chosen as suggested by ASTM E8/E8M standard [11]. The tensile tests were performed in an MTS servo-hydraulic test machine at room temperature, with $1 \mathrm{~mm} / \mathrm{min}$ displacement rate.

Towards to CTOD test, five specimens were obtained, being them machined by wire Electrical Discharge Machining (EDM) with dimensions as per ASTM E1820 standard (SE(B) type specimen). The specimens and their dimensions are presented in Figure 1, considering the geometric limitations of the studied material [9].

The CTOD samples were submitted to fatigue precracking. Afterwards, they received two marks, on both lateral surfaces, with $5 \mathrm{~mm}$ distance between them and equidistant to the precrack tip. These marks were used for the retroreflective tape fixation, which delimited the initial location distance for the laser interferometry and the video analysis. The elongation of the marks was used as an adaptation of the Schwalbe method. The MTS laser extensometer (LX500) was positioned at $378 \mathrm{~mm}$, regarding the focal distance of the equipment, with $45^{\circ}$ to the lateral surface, avoiding the total reflection of the emitted laser to the equipment receptor. The distance difference was acquired

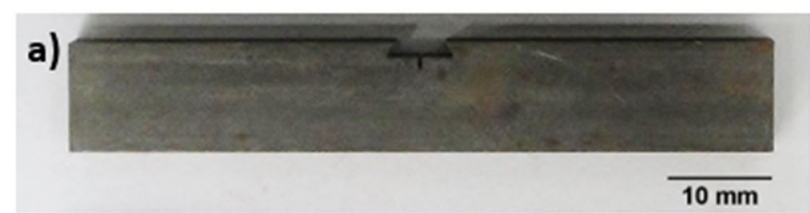

b)

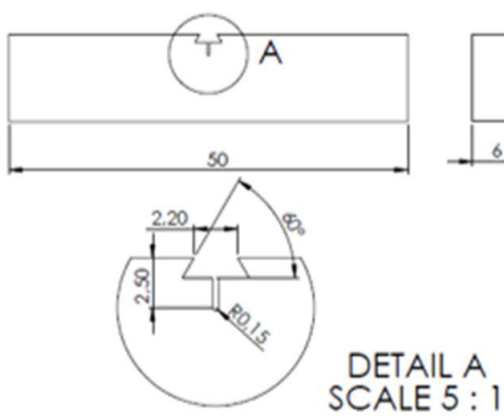

Figure 1. CTOD sample: (a) machined (b) dimensions (in mm). between the retroreflective tapes in each specimen. Later, the data were combined with the values of the load cell for defining the initial and the maximum loading to determine the $\delta_{5}$ of each specimen [12].

Video data were acquired by a Canon $\AA$ camera (PowerShot SX530 HS) with 16.0 Megapixels. These images were scanned through the software Tracker ${ }^{\circledR}$ and related to the load cell to define the initial and the maximum loading for obtaining their correspondent frames. Figure 2 illustrates the software interface, where the arrows indicate the region of interest. The initial and final frames were examined over luminance vs pixel charts, in which the beginning of the tapes is marked as a luminance peak and the end as a luminance valley. Further, differences in the internal distance between both retroreflective tapes (at the beginning and the ending of the test) represent the $\delta_{5}$ values.

The fracture toughness three-point bend tests were performed with $1 \mathrm{~mm} / \mathrm{min}$ displacement rate. After reaching the maximum load by quasi-static bending, the specimens were submitted to a post fatigue procedure for surface investigation. Precrack measurement was done by an Insize projector (ISP-Z3015 model).

For the SZ length, the fracture surfaces were evaluated by a Shimadzu SEM (SSX-550 model). Measurements were done in the central region of each specimen, being one with a $0^{\circ}$ slope (t) and other with a $45^{\circ}$ slope (w) of each surface. Furthermore, the CTOD can be obtained by Equation 1 [6].

$$
\delta=2 \cdot(\mathrm{t} \cdot \sqrt{2}-\mathrm{w})
$$

Each value ( $\mathrm{t}$ or $\mathrm{w}$ ) was determined by a mean of fifteen equidistant points in the fracture surface (selected by image analysis (Image $(\AA)$ ), as the mean measurement was taken and considering the slope angle for obtaining $t$ and w of each specimen. In this way, CTOD can be determined by SZ measurements.

Analysis of variance (ANOVA) was carried out to verify the homogeneity between mean results and to perform Duncan's multiple range tests, in the case of non-homogenous mean values. The Duncan's q-values were compared with the contrasts in a decreasing way, i.e., if the first tested contrast had a value lower than Duncan's indices, the next would have a lower value, making the next step unnecessary; moving to the next one with less mean values to be evaluated $[13,14]$.

\section{Results and discussion}

\subsection{Tensile tests}

Table 2 presents the mechanical properties of the material investigated. The yield strength was determined, considering a $0.2 \%$ strain offset. It is observed that the low

Table 1. Tensile armour wire chemical composition (\% weight)

\begin{tabular}{|c|c|c|c|c|c|c|c|}
\hline Element & $\mathrm{C}$ & Mn & $\mathbf{S}$ & $\mathbf{P}$ & Si & $\mathbf{F e}$ & Other \\
\hline Content & 0.716 & 0.791 & 0.00260 & 0.0120 & 0.194 & 98.1845 & 0.0999 \\
\hline
\end{tabular}




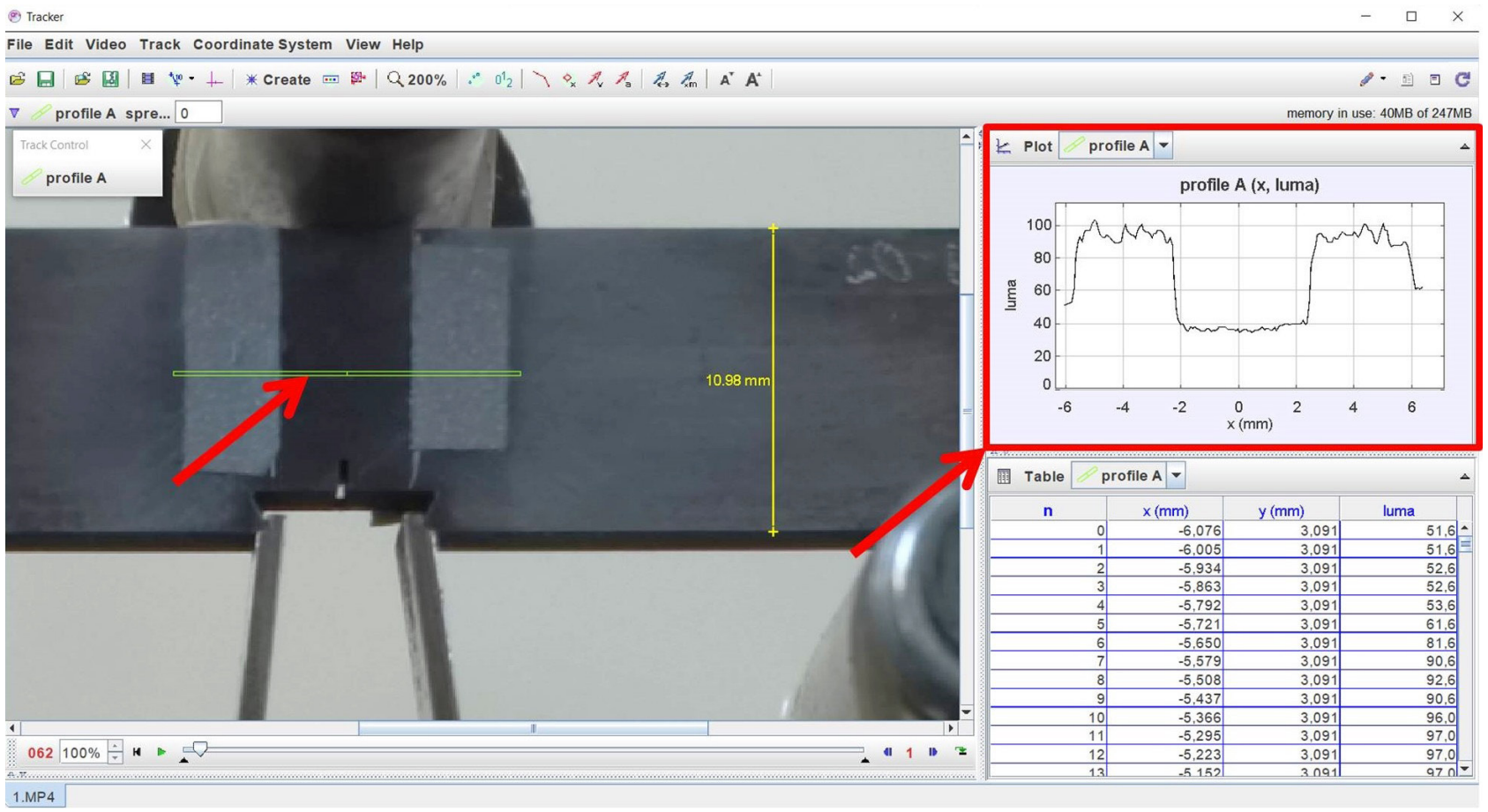

Figure 2. Tracker® interface.

Table 2. Mechanical properties of tensile armour wire studied

\begin{tabular}{cccc}
\hline Specimen & $\begin{array}{c}\text { Yield Strength } \\
\text { (MPa) }\end{array}$ & $\begin{array}{c}\text { Ultimate Tensile Strength } \\
(\mathbf{M P a})\end{array}$ & $\begin{array}{c}\text { Elongation } \\
\mathbf{( \% )}\end{array}$ \\
\hline 1 & 1045 & 1252 & 14.53 \\
2 & 1048 & 1253 & 15.42 \\
3 & 1052 & 1251 & 14.74 \\
Mean & 1049 & 1252 & 14.90 \\
\hline
\end{tabular}

amount of elongation implies in a predominance of a plane strain state, which indicates that this material is expected to have a low CTOD value. Besides, the armour's core and surface present similar results, which allows a comparison between the results obtained via core (SZ and standard) and surface $\left(\delta_{5}\right.$ and video) measurements [15].

\subsection{CTOD tests}

Figure 3 presents the results for all the methodologies, and Table 3 displays their individual CTOD values, including each standard deviation.

As can be verified in Table 3, the material has not large plasticity at the crack tip due to its lower CTOD (standard), and there is a small variation between its findings, which is predicted due to the reproducibility provided by its standardization. However, the standard deviation was higher to laser and SZ methods (ranges were $0.032 \mathrm{~mm}$ and $0.037 \mathrm{~mm}$, respectively) which shows their lower precision $[16,17]$.

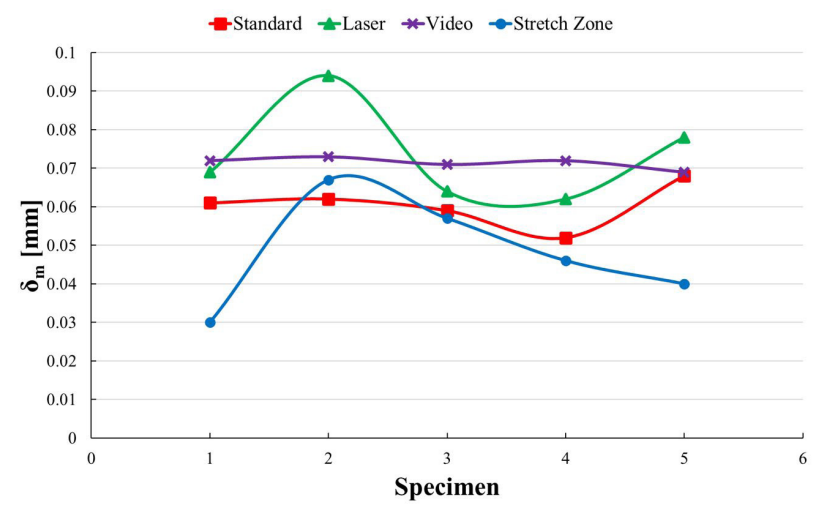

Figure 3. CTOD results.

\subsubsection{Laser}

From the data analysis, the force can be related to the displacement between the retroreflective tapes, generating curves where the limited plastic region can be observed, 
Table 3. Individual CTOD results (in $\mathrm{mm}$ )

\begin{tabular}{ccccccc}
\hline Method & $\mathbf{1}$ & $\mathbf{2}$ & $\mathbf{3}$ & $\mathbf{4}$ & $\mathbf{5}$ & Mean \pm standard deviation \\
\hline Standard & 0.061 & 0.062 & 0.059 & 0.052 & 0.068 & $\mathbf{0 . 0 6 0} \pm \mathbf{0 . 0 0 6}$ \\
Laser & 0.069 & 0.094 & 0.064 & 0.062 & 0.078 & $\mathbf{0 . 0 7 3} \pm \mathbf{0 . 0 1 3}$ \\
Video & 0.072 & 0.073 & 0.071 & 0.072 & 0.069 & $\mathbf{0 . 0 7 1} \pm \mathbf{0 . 0 0 2}$ \\
SZ & 0.030 & 0.067 & 0.057 & 0.046 & 0.040 & $\mathbf{0 . 0 4 8} \pm \mathbf{0 . 0 1 4}$ \\
\hline
\end{tabular}

Table 4. Stretch Zone average measurements results

\begin{tabular}{ccccccc}
\hline Specimen & $\mathbf{1}$ & $\mathbf{2}$ & $\mathbf{3}$ & $\mathbf{4}$ & $\mathbf{5}$ & Mean \\
\hline $\mathbf{t}_{\mathbf{m}}(\mu \mathrm{m})$ & 39.57 & 51.53 & 41.69 & 29.57 & 30.05 & - \\
$\mathbf{w}_{\mathbf{m}}(\mu \mathrm{m})$ & 38.72 & 39.54 & 30.63 & 18.75 & 22.50 & - \\
$\delta_{\mathrm{SN}}(\mathbf{m m})$ & 0.030 & 0.067 & 0.057 & 0.046 & 0.040 & $\mathbf{0 . 0 4 8}$ \\
\hline
\end{tabular}

Table 5. ANOVA analysis

\begin{tabular}{ccccccc}
\hline Source of variation & S.S. & D.F. & Q.M. & P-value & F & F \\
\hline Method & 0.002051 & 3 & 0.000684 & 0.00415 & 6.589861 & \\
Error & 0.00166 & 16 & 0.000104 & & & \\
Total & 0.00371 & 19 & & & & \\
\hline
\end{tabular}

which was necessary to obtain a valid CTOD, evidenced by the beginning of a non-linear region on the curve, which appears as the lateral crack opening occurs $[18,19]$. Thus, as can be seen in Figure 3 (laser results) and illustrated by the standard deviation (Table 3), there was a considerable variation between these findings. In fact, this disparity is mainly between the 2 and 5 samples, and to the others, it could be attributed to a lousy fixation of the retroreflective tapes.

\subsubsection{Video analysis}

In Figure 4, the luminance vs distance is presented as an example, indicating the position of the retroreflective tapes as the region where the crack becomes apparent. Therefore, it was observed that the crack was appearing by the sudden rising in the luminance values when related to the beginning and the ending of the test. This luminance alteration is due to the stress field formed at the crack tip, generating local plastic strains, which are noted by the specimen surface inflexion, i.e., shifting the angle between the normal lateral surface and the crack tip. Thus, this angle shifting affects light incidence and reflection over the crack tip, thus causing changes in the luminance.

\subsubsection{Stretch zone}

Table 4 displays the Stretch Zone (SZ) measurements. The $45^{\circ}$ slope $(\mathrm{t})$ results are slightly superior to that of the $0^{\circ}$ slope (w), and this fact indicates low plasticity at the crack tip, since the crack radius increases when the relation $t / w$ increases, i. e., when the crack blunting occurs, the crack radius is a function of the strain accommodation in this region $[7,20]$.

As can be seen in Figure 5, the SEM images present red lines marking the beginning and ending regions, while the arrows indicate the crack propagation direction. It is

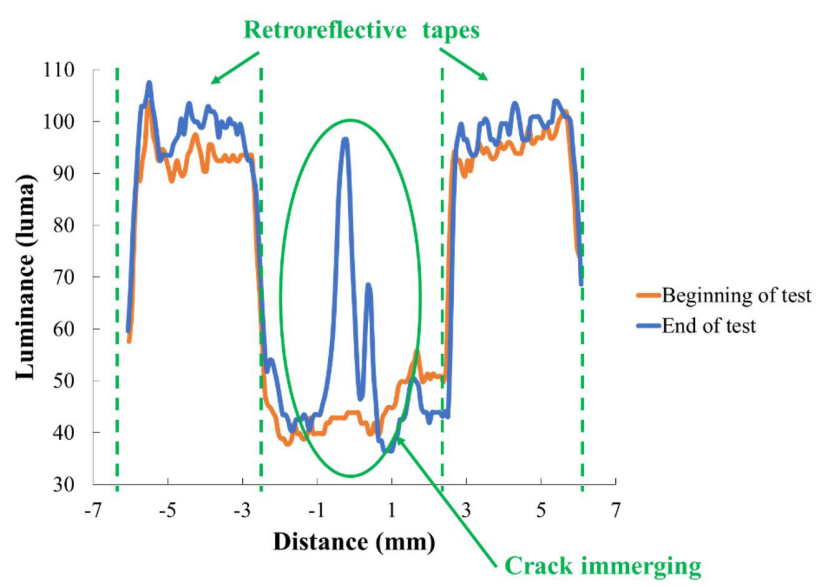

Figure 4. Example of a result obtained via video analysis.

noticed that the SZ findings are lower than the other methods (Table 3), this evidences the difference between the CTOD through indirect techniques in comparison to what occurs at the crack blunting, which is the expected moment to the material reach the maximum CTOD $[9,19]$. The region selected was in the centre of the crack field, thus avoiding locations where the SZ visibility is not clear (as voids or delamination spots). In addition, the SZ is continuous and homogenous in the entire fracture surface for monotonic loading [8,21].

\subsection{Statistical analysis}

By ANOVA analysis, it was found that $\mathrm{F}>\mathrm{F}_{\text {Crit. }}$ at a 95\% confidence level, as shown in Table 5. This result characterizes that the sample means are not homogenous among them, indicating that the CTOD results calculated through different methodologies are not statistically equivalent. Therefore, it became necessary to turn deeper 

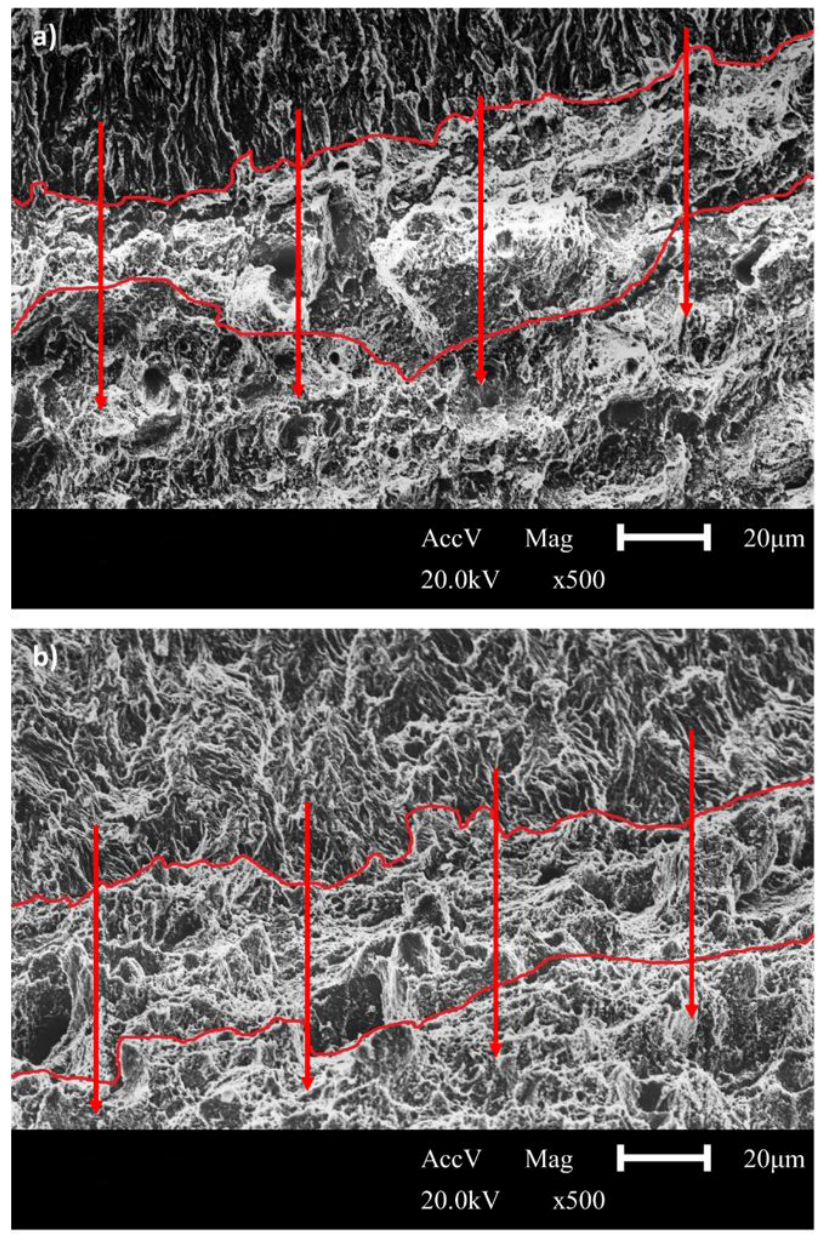

Figure 5. SEM images (a) $0^{\circ}$ slope; (b) $45^{\circ}$ slope.

into the statistical analysis to investigate which average results were heterogeneous [22].

Consequently, it was chosen Duncan's test, also at a $95 \%$ confidence level, in order to group the sample means. The mean values were organized in a decreasing mode, which corresponds to the following order: laser, video, standard and stretch zone. Finally, in Duncan's test, the sample means can be divided into two groups, as presented in Figure 6.

Although results were not homogenous [14,22], all methods were equivalent to the standard, which holds both groups. Therefore, it proves the validity of the techniques

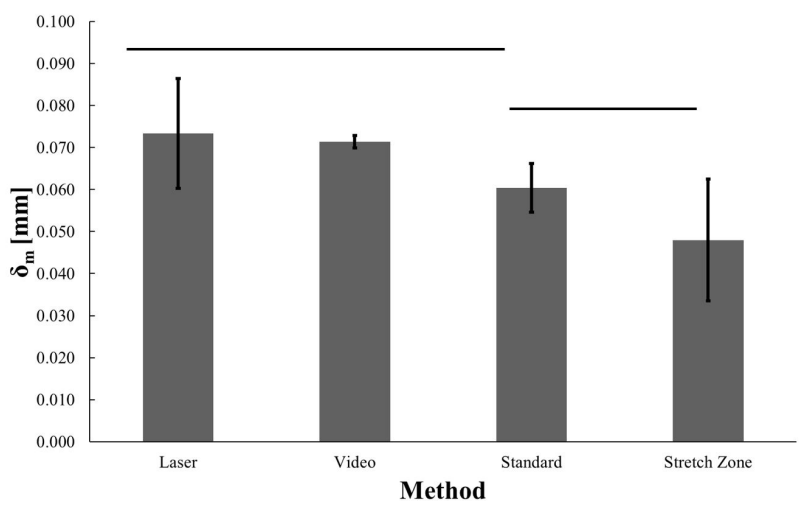

Figure 6. Grouping methods after Duncan's test.

and justifies an alternation among them to determine CTOD values.

\section{Conclusions}

This study presented novel methodologies for fracture toughness by CTOD tests in a tensile wire armour, including the luminance for estimating the CTOD value, which could be applied to obtain characteristics of the strain fields around the cracks. In this context, laser, video, standard and SZ methods were compared among them, resulting in mean values of $0.073 \mathrm{~mm}, 0.071 \mathrm{~mm}, 0.060 \mathrm{~mm}$ e $0.048 \mathrm{~mm}$, respectively. The CTOD values in the SZ were lower than the others, indicating that the techniques for surface sizing and standard did not correspond precisely to the events that occur at the crack tip, notwithstanding providing good approximations. Still, the SZ and the laser techniques were found to be less precise. In ANOVA and Duncan's analysis, it was verified suitability between the innovative techniques and standard. Finally, video was the most accurate method, which suggests its applicability to replace the standard and to provide reliable results.

\section{Acknowledgements}

The authors would like to acknowledge the financial support of CAPES (National Council for Scientific and Technological Development - grant number 23038.000341/2019-71).

\section{References}

1 Schwalbe KH. Introduction of delta-5 as an operational definition of the CTOD and its practical use. Fracture Mechanics. 1995;26:763-778.

2 Castrodeza E, Touça JMR, Perez Ipiña JE, Bastian FL. Determination of CTODC in fibre metal laminates by ASTM and Schwalbe methods. Materials Research. 2002;5(2):119-124. http://dx.doi.org/10.1590/S151614392002000200006.

3 Suresh RKV, Ramakrishnan N, Srinivas M, Ramarao PJ. On the determination of JIC using the stretch zone width method. Journal of Testing and Evaluation. 1999;27(3):211-218. 
4 Ernst HA. Relations between the crack tip opening displacement, $\delta_{5}$, and the modified $\mathrm{J}, \mathrm{J}_{\mathrm{M}}$. Geesthacht: The Crack Tip Opening Displacement in Elastic-Plastic Fracture Mechanics. p. 197-206, 1985.

5 Castrodeza EM, Perez Ipiña JE, Bastian FL. Fracture toughness evaluation of unidirectional fibre metal laminates using traditional CTOD $(\delta)$ and Schwalbe $(\delta 5)$ methodologies. Engineering Fracture Mechanics. 2004;71(7-8):11271138.

6 Sivaprasad S, Tarafder S. Ranganath VR, Das, Sk, Ray KK. Can stretch zone measurements provide a good estimate of fracture toughness? In Proceedings of the 10th International Congress of Fracture (ICF10); 2001; Honolulu, Hawaii. Honolulu: ICF; 2001.

7 Saxena S, Ramakrishnan N, Dutta BK. Determination of stretch zone width using fem. Engineering Fracture Mechanics. 2009;76(7):911-920. http://dx.doi.org/10.1016/j.engfracmech.2008.12.015.

8 Schwalbe KH, Heerens J, Hellmann D, Cornec A. Relationships between various definitions of the crack tip opening displacement. Geesthacht: The Crack Tip Opening Displacement in Elastic-Plastic Fracture Mechanics; 1985. p. 133-153.

9 ASTM International. ASTM E1820: standard test method for measurement of fracture toughness. West Conshohocken: ASTM; 2017.

10 Tagliari MR, Antunes MR, Santos JGN, Santos FP, Santos JMC, Falcade T, et al. Tensile armor wires submitted to slow strain rate tests in a corrosive environment and cathodic protection: a comparison between two different microstructures. Materials Research. 2019;22(3):e20180465. http://dx.doi.org/10.1590/1980-5373-mr-2018-0465.

11 ASTM International. ASTM E8/E8M: tension testing of metallic materials. West Conshohocken: ASTM; 2015.

12 Hellman D, Schwalbe KH. Fracture Mechanics: Fifteenth Symposium. ASTM Special Technical Publication. 1984;833:577-603.

13 Farias AML, Demarqui FN. Análise de variância. 1. ed. Rio de Janeiro: UFF; 2017.

14 Duncan DB. Multiple range and multiple F tests. Biometrics. 1955;11(1):1-42.

15 Potter JM. Fatigue and fracture testing of weldments. Vol. 1058. West Conshohocken: ASTM International; 1990.

16 Chiodo SG. Procedimento de avaliação da integral J e CTOD para dutos com trincas circunferenciais submetidos à flexão e aplicações à Instalação de risers pelo método carretel [dissertação]. São Paulo: USP; 2009.

17 Anderson TL. Fracture mechanics: fundamentals and applications. 3rd ed. Boca Raton: Taylor \& Francis; 2004.

18 Tendela LP, Galizzi GE. Interferometric displacement measurement on scattering surfaces utilizing speckle effect Interferometric displacement measurement on scattering surfaces utilizing speckle effect. Journal of Physics. E, Scientific Instruments. 1970;3:214-218.

19 Ohtsuka Y, Itoh K. Two-frequency laser interferometer for small displacement measurements in a low frequency range. Applied Optics. 1979;18(2):219-224. http://dx.doi.org/10.1364/AO.18.000219.

20 Liu P, Zhang G, Zhai T, Feng K. Effect of treatment in weld surface on fatigue and fracture behavior of titanium alloys welded joints by vacuum electron beam welding. Vacuum. 2017;141:176-180. http://dx.doi.org/10.1016/j. vacuum.2017.04.019.

21 Chowdhury T, Sivaprasad S, Bar HN, Tarafder S, Bandyopadhyay NR. Stretch zone formation in cyclic fracture of 20MnMoNi55 pressure vessel steel. Engineering Fracture Mechanics. 2015;148:60-72. http://dx.doi.org/10.1016/j. engfracmech.2015.09.026.

22 Souza AM, Ethur ABM, Lopes LFD, Zanini RR. Introdução a projetos de experimentos. 1. ed. Santa Maria: UFSM; 2002.

Received: 17 Aug. 2020

Accepted: 22 Set. 2020 